\title{
Is the World Flat or Spiky? Information Intensity, Skills, and Global Service Disaggregation
}

\author{
Sunil Mithas \\ Decision and Information Technologies, Robert H. Smith School of Business, University of Maryland, \\ College Park, Maryland 20742, smithas@rhsmith.umd.edu \\ Jonathan Whitaker \\ Management Department, Robins School of Business, University of Richmond, Richmond, Virginia 23173, \\ jwhitaker@richmond.edu
}

\begin{abstract}
$\mathrm{W}^{\mathrm{s}}$ hich service occupations are the most susceptible to global disaggregation? What are the factors and mechanisms that make service occupations amenable to global disaggregation? This research addresses these questions by building on previous work by Apte and Mason (1995) and Rai et al. (2006) that focuses on the unbundling of information and physical flows. We propose a theory of service disaggregation and argue that high information intensity makes an occupation more amenable to disaggregation because the activities in such occupations can be codified, standardized, and modularized. We empirically validate our theoretical model using data on more than 300 service occupations. We find that at the mean skill level, the information intensity of an occupation is positively associated with the disaggregation potential of that occupation, and the effect of information intensity on disaggregation potential is mediated by the modularizability of an occupation. We also find that skills moderate the effect of information intensity on service disaggregation.

Furthermore, we study the patterns in U.S. employment and salary growth from 2000 to 2004. Contrary to popular perception, we do not find any adverse effect in terms of employment growth or salary growth for high information-intensity occupations at the mean skill level. Our findings show that high-skill occupations have experienced higher employment and salary growth than low-skill occupations at the mean level of information intensity. Notably, high information-intensity occupations that require higher skill levels have experienced higher employment growth, though this employment growth is accompanied by a decline in salary growth. Occupations with a higher need for physical presence have also experienced higher employment growth and lower salary growth. Overall, these results imply that firms and managers need to consider the modularizability of occupations as they reallocate global resources to pursue cost and innovation opportunities. For individual workers, our results highlight the importance of continuous investments in human capital and skill acquisition because high information-intensity and high-skill occupations appear to be relatively less vulnerable to global disaggregation.
\end{abstract}

Key words: information intensity; skills; codifiability; standardizability; modularizability; offshoring; global disaggregation; service occupations; services; need for physical presence

History: Arun Rai, Senior Editor. This paper was received on August 15, 2005, and was with the authors

11 months for 3 revisions.

\section{Introduction}

Firms are outsourcing information technology (IT) and professional service jobs to remote locations to leverage global talent, reduce costs and cycle time, and spur innovation (Lacity et al. 2003, Rottman and Lacity 2004, Sobol and Apte 1995). IT figures prominently among the forces that have facilitated the offshoring and global disaggregation of service occupations, leading to a "flat world" phenomenon with the potential to affect the employment and wages of knowledge workers (Apte and Mason 1995, Carmel and Agarwal 2002, Friedman 2005, Samuelson 2004, Venkatraman 2004). In contrast, Florida portrays a "spiky" world, in which a small number of cities and regions with a high concentration of skilled and creative workers drive the global economy, with the tallest peaks "growing even higher, while the valleys mostly languish" (2005, p. 48). Several other studies also suggest that digital platforms do not always imply disaggregation and that skills, along with geographical and cultural distance, may impede service disaggregation (Apte and Mason 1995, Autor et al. 2003, Bhagwati 
et al. 2004, Blinder 2006, Levy and Murnane 2004, Olson and Olson 2000).

Information systems (IS) researchers have used firms (Rai et al. 2006, Whitaker et al. 2005) and manufacturing plants (Bardhan et al. 2007, 2006) to study the role of IT in enabling the unbundling of information and physical flows and the outsourcing of business processes, but they do not explain why information -intensive occupations are more amenable to service disaggregation, and they do not describe the mechanisms that facilitate or inhibit service disaggregation. Because decision making for resource allocation takes place at the occupation level (i.e., firms hire or retrench employees who belong to certain occupations; see Thurm 2007) and because individual employees invest in their human capital to prepare for certain occupations (Mithas and Krishnan 2007), it is important to understand the role of occupational attributessuch as information intensity, skill level, and the need for physical presence-in service disaggregation to advance theory and inform managerial and individual decision making.

In this study, we draw on previous research (Apte and Mason 1995, Rai et al. 2006) to develop a theory of service disaggregation. We identify the codifiability, standardizability, and modularizability of an occupation as mediating mechanisms for the effect of information intensity on the global disaggregation of services. The mediation reasoning is consistent with recent work that finds broad support for how IT platforms enable the unbundling of information and physical flows by ensuring data consistency and near-real-time, cross-functional application systems integration (Rai et al. 2006). We also draw on the economics literature to study the moderating effect of skills on the relationship between information intensity and service disaggregation (Autor et al. 2003, Levy and Goelman 2005, Levy and Murnane 2004). We use primary and archival data on more than 300 U.S. service occupations to validate our theoretical model. Finally, we study the effects of information intensity, skill level, and the need for physical presence on U.S. employment growth and salary growth from 2000 to 2004. The results of this additional analysis provide evidence contrary to popular perceptions and suggest useful management and policy guidelines.

We structure the remainder of this paper as follows: Section 2 describes the theoretical framework and research hypotheses. Section 3 describes the research design and methodology. Section 4 provides data analysis, results, discussion, and concluding remarks.

\section{Theory}

We build on the conceptual work by Apte and Mason (1995), who classify service activities into information actions (manipulation of symbols), physical actions (manipulation of physical objects), interpersonal actions (dealing with internal and external customers), and non-value-adding actions. These actions constitute the characteristics of an occupation. Information actions are related to the information intensity of an occupation, physical actions are related to the need for physical presence in an occupation, and interpersonal actions are related to the need for customer contact in an occupation. Apte and Mason argue that these characteristics-information intensity, the need for physical presence, and the need for customer contact-explain the global disaggregation potential of service occupations.

This paper extends Apte and Mason's conceptual work in two ways. First, we posit that codifiability, standardizability, and modularizability are mediating mechanisms for the effect of information intensity on service disaggregation. Second, we empirically validate our model by studying the effect of information intensity and the need for physical presence on disaggregation potential (employment and salary growth) of service occupations. Figure 1 shows our conceptual model.

\subsection{Information Intensity and Service Disaggregation}

Porter and Millar (1985) are among early researchers to use the concept of information intensity in the

Figure 1 Conceptual Model

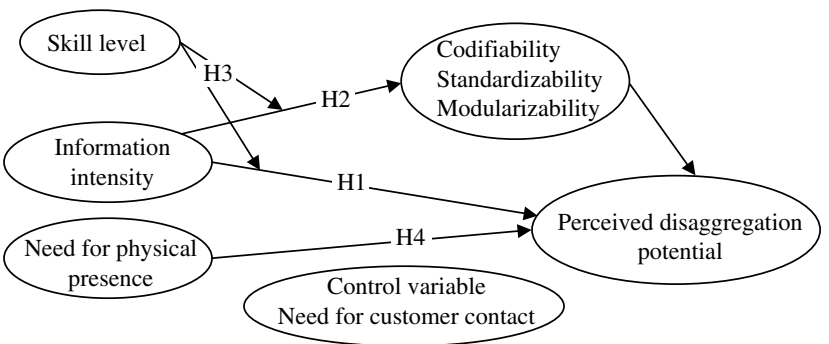

Note. Skill level is posited to be a quasimoderator in the conceptual model. 
context of activities in the value chain of a firm. They argue that each value chain activity has two components, an information-processing component and a physical component, and they suggest that IT enables firms to reconfigure their value chains by transforming these two components. For example, IT has substituted machines for human effort, enabled improved information sharing up and down the value chain, and decoupled information processing from physical processing.

Apte and Mason (1995) extend Porter and Millar's (1985) framework and define the information intensity of a service activity as the ratio of the time spent dealing with information to the total time in that activity. Apte and Mason argue that the information intensity of an occupation allows for greater use of IT to exploit cost differences and access global talent, thus enabling service disaggregation. Evans and Wurster (1997) provide support for this idea and argue that interconnected communication networks enable firms to delink the information and physical components of their goods and services, deconstruct their existing value chains, and reconfigure their business models in new ways to achieve competitive advantage. Hagel and Singer (1999) extend this reasoning and suggest that IT platforms enable firms to unbundle the three core processes (customer relationship management, product innovation, and infrastructure management) and to manage these as three separate businesses, focusing on the economies of scope, speed, and scale that each process requires. The unbundling of business processes gives firms greater flexibility to locate their facilities where each process can be performed and delivered in the most efficient and effective manner.

Following Apte and Mason, we treat information intensity of an occupation as a variable that is dependent on the extent to which it is possible to use the capability of an "information technology solution for manipulating symbols (i.e., collecting, processing, and disseminating symbols)" (1995, p. 1256) in that occupation. Other studies have also established a strong connection between the concept of information intensity and the use of IT. Porter and Millar (1985) note that information-intensive industries were among the early users of IT, and Jarvenpaa and Ives (1990) empircally verify the relationship between industry information intensity and IT use. Recent research has also suggested that products and services with higher information intensity have greater potential to benefit from IT (Andal-Ancion et al. 2003, Dehning et al. 2003). Studies at the industry (Han et al. 2005), firm (Whitaker et al. 2005), and plant (Bardhan et al. 2007, 2006) levels show that higher IT intensity results in greater use of outsourcing or disaggregation, perhaps because higher IT intensity allows for the separation in time and space of information-intensive activities from physical manipulation activities.

Therefore, from this point onward, we develop the theory and hypotheses in terms of information intensity, but we illustrate our discussion using examples of IT tools and their use. Because IT is the exogenous factor that managers can manipulate to influence the information intensity of an occupation, our focus on IT tools is consistent with Thomas and Tymon's (1982) recommendation to translate abstract concepts into specific variables to serve the practitioner need for operational validity; it is also consistent with the counterfactual or potential outcomes approach for causal interpretation of findings (Dehejia and Wahba 2002, Holland and Rubin 1983, Mithas et al. 2006, Rosenbaum and Rubin 1983). ${ }^{1}$ This approach enables us to maintain the theoretical linkages consistent with previous research while ensuring practical and managerial relevance of the findings.

Although previous research has noted that the information intensity of a service occupation is positively associated with greater disaggregation potential, there has not been a systematic empirical study of this association and the mediating mechanisms. ${ }^{2} \mathrm{We}$ extend the previous theoretical work and suggest that

\footnotetext{
${ }^{1}$ IT can be viewed as a treatment to which all occupations are "potentially exposable" (see Holland and Rubin 1983). Because this is perhaps the first empirical study to investigate the role of IT in service disaggregation at the occupational level, and because we treat our results as associational, the notion of potential exposability to IT will allow future research to explore the causal implications.

${ }^{2}$ Apte and Mason $(1995$, p. 1256) recognize some of these mechanisms without specifically naming them. For example, they argue that IT is more likely to facilitate service disaggregation if activities are "more well-structured and specific" and when some components of activities are "separable" from other components. Some similarities are noticeable between the notions of structuredness, specificity, and separability that Apte and Mason use and the notions of codifiability, standardizability, and modularizability that
} 
three related but conceptually distinct intervening variables-codifiability, standardizability, and modularizability-mediate the relationship between information intensity and disaggregation potential. We argue that jobs with greater codifiability, standardizability, and modularizability are more amenable to leveraging the "plug-and-play" potential of IT. This reasoning is consistent with recent research that identifies the concepts of codifiability, standardizability, and modularizability and their relationship to IT. For example, Sambamurthy et al. (2003, p. 247) identify the role of IT in the creation of digitized work processes and knowledge systems with high reach and richness that enabe firms to tie activity and information flows across "geographical regions." We build on this research by more fully eliciting and expounding on these concepts and relationships and by placing them in the context of global disaggregation of service occupations. Next, we define the mechanisms of codifiability, standardizability, and modularizability and then theorize how the effect of information intensity on disaggregation potential is mediated through these mechanisms.

2.1.1. Codifiability. Codifiability is the extent to which knowledge can be converted into a form that is suitable for transfer across economic agents (Ancori et al. 2000). In an occupation context, codifiability is the extent to which the activities in an occupation can be described completely in a set of written instructions. Note that the codifiability of an occupation depends on the content of that occupation. Occupations and activities within occupations with a high proportion of tacit knowledge are less codifiable than those that use explicit knowledge. To use the software development context as an example, the requirements-definition phase, which involves the tacit firm- and context-specific knowledge of a client and the varied expectations of its multiple stakeholders, is significantly less codifiable (Carmel and Tjia 2001, Choudhury and Sabherwal 2003) than the programming phase once requirements have been defined and made explicit. The need to achieve codifiability in requirements definition explains why IT

are used in this study. The authors thank an anonymous reviewer for drawing attention to these similarities. service providers frequently maintain a small design team at the client site. ${ }^{3}$

As noted previously, because the information intensity of an occupation represents the extent to which an occupation is amenable to the use of IT, we now discuss how IT tools enable codifiability. Previous research suggests that IT and IT-enabled codification tools make it possible to represent and reconfigure business processes. For example, Huber (1990) notes that IT facilitates the recording and retrieval of information about organizational processes, which makes process formalization more viable. Similarly, Malone et al. (1999) argue that process representation approaches, such as flow charts, data flow diagrams, state transition diagrams, and goal-based models, have facilitated the development of a process grammar to describe complex processes. The use of codification tools, such as process grammar and metagraphs, can enable the decomposition, reconfiguration, and synthesis of business processes, aiding in the coordination and management of dependencies across processes and spatially dispersed business units.

An example of an IT system that facilitates codifiability of business processes is computer-aided software engineering (CASE) tools, which have played a key role in the codification of firms' systems development knowledge. Purvis et al. (2000) describe how CASE repositories codify the four knowledge domains-IS planning, business analysis, design, and construction-by storing business strategy and function matrices, data and process models, process decomposition and data flow diagrams, and program structure charts. CASE repositories provide a foundation for IT development organizations to use this codified knowledge and compete more effectively and efficiently (Purvis et al. 2000). Other IT systems that facilitate codifiability appear in Table 1.

Beyond the software engineering context, the IT enablement of other firmwide business processes has also contributed to codifiability and disaggregation. For example, implementation of enterprise resource planning (ERP) systems at large firms over the past 15 years has involved the preparation of detailed flow

\footnotetext{
${ }^{3}$ The authors thank an anonymous reviewer for suggesting this illustration.
} 
Table 1

Codifiability, Standardizability, and Modularizability

\begin{tabular}{|c|c|c|c|}
\hline & Codifiability & Standardizability & Modularizability \\
\hline Brief description & $\begin{array}{l}\text { The extent to which knowledge can be } \\
\text { converted into a form suitable for } \\
\text { transfer across economic agents }\end{array}$ & $\begin{array}{l}\text { A common framework and vocabulary } \\
\text { to define business processes }\end{array}$ & $\begin{array}{l}\text { The decomposition of a product or service } \\
\text { into components }\end{array}$ \\
\hline $\begin{array}{l}\text { Role of IT and } \\
\text { information intensity }\end{array}$ & $\begin{array}{l}\text { IT enables firms to represent and record } \\
\text { information about business processes. }\end{array}$ & $\begin{array}{l}\text { IT provides tools for firms to store and } \\
\text { access a repository of business } \\
\text { processes. }\end{array}$ & $\begin{array}{l}\text { IT tools provide capacity to transfer and } \\
\text { access process knowledge from } \\
\text { anywhere and ease monitoring and } \\
\text { communication. }\end{array}$ \\
\hline $\begin{array}{l}\text { IT tools and applications } \\
\text { that facilitate } \\
\text { codifiability, } \\
\text { standardizability, and } \\
\text { modularizability }\end{array}$ & $\begin{array}{l}\text { - } \text { - PASE } \\
\text { - Process mapping during enterprise } \\
\text { resource planning implementations }\end{array}$ & $\begin{array}{l}\text { - Product lifecycle management } \\
\text { - Web services and service-oriented } \\
\text { architecture } \\
\text { - Customer relationship management }\end{array}$ & $\begin{array}{l}\text { - Configuration management systems } \\
\text { - Virtual workspaces } \\
\text { - Web services }\end{array}$ \\
\hline $\begin{array}{l}\text { Role in service } \\
\text { disaggregation }\end{array}$ & $\begin{array}{l}\text { Codifiability enables process knowledge } \\
\text { to be captured, specialized, reduced to } \\
\text { a set of instructions, and distributed, } \\
\text { which enables the split of service } \\
\text { activities across business units and } \\
\text { firm boundaries. }\end{array}$ & $\begin{array}{l}\text { Standardizability enables a firm to } \\
\text { communicate how a process operates } \\
\text { and to perform handoffs across } \\
\text { processes and across firms. }\end{array}$ & $\begin{array}{l}\text { Modularization of business processes } \\
\text { enables spatially dispersed groups to } \\
\text { receive inputs of incoming business } \\
\text { processes and feed outputs into } \\
\text { outgoing processes in a seamless } \\
\text { manner. }\end{array}$ \\
\hline Occupation example & $\begin{array}{l}\text { Software requirements definition, which } \\
\text { involves tacit knowledge, is less } \\
\text { codifiable than programming once } \\
\text { requirements have been explicit. }\end{array}$ & $\begin{array}{l}\text { A fast-food cashier can be trained to } \\
\text { follow a standard process with every } \\
\text { customer, whereas a trial lawyer may } \\
\text { need to follow a different process for } \\
\text { each trial. }\end{array}$ & $\begin{array}{l}\text { Although multiple technical writers can } \\
\text { each separately write a chapter for a } \\
\text { user manual, it is more difficult to } \\
\text { modularize the occupation of artistic } \\
\text { painter. }\end{array}$ \\
\hline References & $\begin{array}{l}\text { - Ancori et al. (2000) } \\
\text { - Cohendet and Steinmueller (2000) } \\
\text { - Huber (1990) } \\
\text { - Purvis et al. (2000) }\end{array}$ & $\begin{array}{l}\text { - Davenport (2005) } \\
\text { - Drezner (2004) } \\
\text { - Malone et al. (1999) }\end{array}$ & $\begin{array}{l}\text { - Carmel and Agarwal (2002) } \\
\text { - Gershenson et al. (2003) } \\
\text { - Sambamurthy et al. (2003) } \\
\text { - Zenger and Hesterly (1997) }\end{array}$ \\
\hline
\end{tabular}

charts to map business processes, which were then embedded into workflow features of the ERP systems. As a recent BusinessWeek article notes,

Genpact, Accenture, IBM Services, or another big outsourcing specialist dispatches teams to meticulously dissect the workflow of an entire human resources, finance, or info tech department. The team then helps build a new IT platform, redesigns all processes, and administers programs, acting as a virtual subsidiary. The contractor then disperses work among global networks of staff ranging from the U.S. to Asia to Eastern Europe. (Engardio 2006, p. 55)

Why does codifiability facilitate service disaggregation? Codifiability enables knowledge to be captured, specialized, reduced to a set of instructions, and distributed, which contributes to modifying the spatial organization and division of labor (Cohendet and Steinmueller 2000). Kellogg and Chase (1995) suggest that codifiability of information enables more loosely coupled contact between the customer and the service provider. Codifiability enables an improved specification of roles, goals, operating procedures, and contractual obligations to facilitate the split of service activities across business units and firm boundaries (Demarie and Hitt 2000). Although it may be more difficult to codify activities in some occupations with a high proportion of tacit knowledge, researchers and practitioners have noted the potential for such occupations to achieve codifiability as firms achieve greater process maturity and deploy more sophisticated IT systems (Baark 1999, Carmel and Agarwal 2002, Engardio et al. 2005, Martin 2006). For example, Sambamurthy et al. note that sophisticated IT systems are "alleviating concerns that the use of IT for knowledge processes is strictly limited to codifiable or explicit knowledge" (2003, p. 250). The increasing use of offshore locations for activities related to design, research and development (R\&D), and innovation testifies to this trend (Lewin and Couto 2006, Ricadela 2006).

2.1.2. Standardizability. Standardizability arises out of the process of achieving a common framework and vocabulary to describe business processes 
(Davenport 2005). In an occupation context, standardizability is the extent to which the activities in an occupation can be performed successfully using a set of consistent and repeatable processes. The consistency of processes applies across different workers, cases, and business units. For example, the occupation of fast-food cashier is more standardizable than the occupation of trial lawyer. Fast-food cashiers can be trained to follow the same process with every customer (greet customers, ask for their orders, enter their orders, etc.). Conversely, a trial lawyer may need to follow a different process for each trial, depending on the issues involved, and two different trial lawyers may follow a different process even for the same trial.

How does IT facilitate the standardizability of an occupation? IT facilitates process standardization by providing the tools to codify processes and the tools to store and access a repository of business processes (Malone et al. 1999). For example, product lifecycle management systems facilitate standardizability of complex design-related business processes in the automotive industry. Web services and service-oriented architecture enable standardizability by invoking consistent business processes across spatially and legally separate business units and organizational members (McDougall 2006). Similarly, the use of the same customer relationship management system by dispersed sales teams enables consistent information delivery and usage by all the members of a sales force. For example, IBM is currently using IT tools "for turning each kind of service into a series of standardized processes. The tasks are then broken into pieces and moved electronically between people who perform them" (Hamm 2006, p. 110).

Why does standardizability facilitate service disaggregation? Standardizability of a business process enables a firm to communicate more effectively how the business operates, perform handoffs across processes, and benchmark performance (Davenport 2005). The ease of handoffs applies for processes within an organization and across organizations. As Drezner (2004) notes, "One thing that has made offshore outsourcing possible is the standardization of such business tasks as data entry, accounting, and IT support." For example, the capability maturity model (formerly CMM, now CMMI), developed by the Software Engineering Institute at Carnegie Melon University, is a process management standard to achieve greater consistency in software development (Paulk 1995). A vendor's CMMI certification provides assurance about its capability to work effectively in a spatially dispersed manner and has greatly facilitated the growth of outsourcing for software development (Davenport 2005). Similarly, the spread of ISO 9000 in the early 1990s also facilitated global trade by providing a standard framework to understand vendor business processes and quality levels.

2.1.3. Modularizability. In a manufacturing context, modularizability involves the decomposition of a product into subassemblies and components (Gershenson et al. 2003). Although the idea of modularizability has been extensively used in the manufacturing context, it has only recently been used in the services context (Baldwin and Clark 1997). We extend the notion of modularizability to the occupation level and define the modularizability of an occupation as the extent to which the activities in an occupation can be separated into components so that the components can be performed independently by separate people and then later be integrated. For example, the occupation of technical writer is more modularizable than the occupation of artistic painter. For technical writing, one writer can write a chapter of a user manual, and another writer can write another chapter of a user manual, and both chapters can be placed in the manual. In contrast, it is much more difficult to modularize activities involved in creating an artistic painting because of the interdependence and inseparability of the patterns and visual imageries on a single canvas.

How does IT facilitate the modularizability of an occupation? IT facilitates the execution and delivery of modular business processes in two ways. First, IT tools provide the capacity to transfer and access process knowledge across firm and geographic boundaries, thus enabling seamless functioning of modular business processes (Cohendet and Steinmueller 2000). Second, IT facilitates the transfer and coordination of processes across firm boundaries by easing monitoring and communication (Zenger and Hesterly 1997). As Sambamurthy et al. note, "Digitization technologies have...enabled the creation of atomized and modular business processes that...can be accessed from anywhere through electronic interfaces, greatly enhancing their reach" (2003, p. 247). For example, 
IT systems enable IBM to make its data centers and associated business processes interchangeable, so IBM can easily reroute traffic if there are disruptions in any part of its network (Hamm 2006). Web services encapsulate modular business processes in separate IT applications and utilities, enabling firms to minimize the interdependencies across different modules without sacrificing flexibility or responsiveness. Configuration management systems allow widely dispersed software teams to access the current version of an artifact, enabling parallel work by different team members while maintaining version control.

Why does modularizability facilitate service disaggregation? The modularization of business processes enables spatially dispersed groups to receive the inputs of incoming business processes and feed the outputs into outgoing business processes in a seamless manner. Although Apte and Mason do not use the term "modularizability," they allude to this notion by specifying the following necessary condition: "The symbolic manipulation component of the activity is separable. It can be isolated and disembodied from the customer contact component and the physical object manipulation component of the activity" (1995, p. 1256). Gosain et al. (2005) show that modular design of interconnected processes is associated with greater supply chain flexibility, which in turn enables firms to adapt their offerings and supply chain partners in response to changing business requirements. Carmel and Agarwal note that

increasingly modular design of software production has reduced transaction costs-that is, the cost of coordinating software development and support work between two or more parties. More modular software production eases the burden of synchronizing, communicating, traveling, monitoring, providing feedback, and enforcing software development contracts. (2002, p. 66)

To summarize our discussion thus far, by facilitating codifiability, standardizability, and modularizability, IT systems make it possible to separate business processes and artifacts from the places where the processes were traditionally performed. We next illustrate these concepts using three example occupations: accountant/auditor, aerospace engineer, and radiologist.
2.1.4. An Illustration Using Three Occupations. Consider the occupation of an accountant/auditor. The primary responsibilities of an audit firm are to review a client's accounting transactions and processes and to certify the client's financial statements. IT helps codify the auditor's role by enabling auditordefined heuristics and predefined audit tests to be stored electronically in command buttons and control agents (Rezaee et al. 2002). For standardizability, computer-assisted audit tool modules embedded in client software automatically filter prespecified transactions and create system audit control files (Zhao et al. 2004). For modularizability, an audit data mart stores the audit control files for subsequent review, and online systems enable audit team members to separately maintain and update various sections of the audit workpapers and audit report.

The occupation of aeropsace engineer provides another example of how IT can facilitate codifiability, standardizability, and modularizability. Argyres (1999) provides a rich discussion of the use of IT by four engineering firms to collaborate (from different locations) on design and development of the B-2 "Stealth" bomber. IT helped codify the engineering process through a product definition system that encoded modeling procedures and supplied a common technical grammar to define and transmit design and part information. The engineering process was standardized in part by data filters that screened engineer submissions of models and drawings and approved only the updates that met prespecified requirements. For modularizability, the engineering firms used structural engineering software to define nodes at interfaces between the various product components. Once interface nodes were defined, each engineer could work on the part(s) for which he or she was responsible.

Finally, IT plays a role in the codification, standardization, and modularization of the radiologist occupation (Karmarkar 2004). Specifically, IT facilitates codifiability by enabling high-resolution digitization of computed tomography scans and transmission of the scans for offsite review. For standardizability, an initial screen of radiology images for abnormal patterns can be performed by computer-assisted diagnostic software. For modularizability, workflow systems enable radiology order entry, image review, 
and communication of results between a physician and a radiologist on a real-time or an asynchronous basis (Solovy 2002).

The preceding discussion illustrates how the information intensity of these occupations has allowed IT tools to codify, standardize, and modularize the activities, theoretically making some of these occupations suitable for global disaggregation. ${ }^{4}$ To summarize, information intensity makes service occupations more amenable to global disaggregation because IT enables a firm to codify, standardize, and modularize the large, cross-functional processes involved in such occupations and disaggregate and transfer specific processes to remote service providers, while managing dependencies and seamlessly integrating outcomes of outsourced processes back into the firm's internal operations. Therefore, we posit that relatively higher information-intensive occupations will have greater disaggregation potential. In addition to considering a direct effect of information intensity on disaggregation, we must also consider the effect of information intensity on disaggregation mediated through the codifiability, standardizability, and modularizability of an occupation. Thus,

Нүротнеsis 1. Occupations with higher information intensity have greater disaggregation potential than occupations with lower information intensity.

Hypothesis 2. The effect of information intensity on the disaggregation potential of an occupation is mediated through the (a) codifiability, (b) standardizability, and (c) modularizability of the occupation.

\subsection{Skill Level and Service Disaggregation}

In addition to information intensity, the skill level of an occupation also plays an important role in service disaggregation. An occupation can be categorized as high skill versus low skill based on the extent to which the occupation requires cognitive and analytical abilities and the extent to which the occupation

\footnotetext{
${ }^{4}$ In some cases, legal or strategic considerations may impede global service disaggregation (for regulatory challenges to the offshoring of radiology, see Levy and Goelman 2005), thus making our hypothesis tests even more conservative. This is because the presence of these considerations tends to favor the null hypotheses that relates information intensity to codifiability, standardizability, modularizability, and perceived disaggregation potential.
}

is amenable to rule-based or pattern-recognition logic (Autor et al. 2003, Berman et al. 1994). High-skill occupations, typically operationalized as those that require a college degree, involve nonroutine problem solving, such as detecting and responding to exceptions, and expert thinking and complex communication that typically come with years of on-the-job practice and learning. Such occupations require cognitive and analytical abilities to identify and solve abstract problems and flexibility to respond to unanticipated contingencies. Conversely, low-skill occupations involve simple, repetitive, and routine tasks and are typically operationalized as requiring a high school education.

We posit that high-skill occupations are less vulnerable to service disaggregation because they involve higher-order cognitive skills that are not easily captured in rules, making these high-skill occupations less codifiable and standardizable. Furthermore, highskill occupations are less modularizable because they require a comprehensive view of the problem and dealing with a range of stakeholders (e.g., customers, suppliers, colleagues, subordinates) to develop solutions (Bresnahan et al. 2002). Our arguments are consistent with previous research that suggests that computers are more likely to facilitate substitution of jobs that can be performed by following a rulebased logic (Levy and Murnane 2004). We suggest that computer-enabled substitution of tasks and offshoring of occupations are variations on a common theme; whereas the former shifts routine tasks to computers, the latter involves transferring rule-based and routine tasks that require human intervention but do not require significant expert thinking or complex communication to an offshore location. Typically, such occupations do not require high-level education and are at the lower end of the skill spectrum. In contrast, high-skill occupations that require expert thinking and complex communication are less suitable for service disaggregation.

Several empirical studies provide support for these arguments. For example, researchers have argued that the use of computers and other advanced technologies is associated with an increased demand for highly skilled labor (Berman et al. 1998, Bresnahan et al. 2002, Lawrence and Slaughter 1993, Levy and Murnane 1992, Machin and Van Reenen 1998). Feenstra (1998) argues that low-skill occupations are 
more vulnerable to offshoring than are high-skill occupations. Mithas and Krishnan (2007) report that firms value IT professionals with higher education levels significantly more than IT professionals with lower education levels, which is consistent with similar findings on other professions in the economics literature (Levy and Murnane 1992).

We also expect that skill level has a negative moderating effect on the relationship between information intensity and disaggregation potential, for two reasons. First, information-intensive occupations typically use newer plants and technologies and require workers with higher skill levels to manage these technologies, making high-skill occupations relatively less vulnerable to service disaggregation. An industrylevel study by Bartel and Lichtenberg (1987) provides support for this argument by showing that the relative demand for educated workers declines as the plant and its equipment age.

Second, high information-intensity and high-skill occupations require higher-order cognitive skills and take a long time to learn, practice, and master (Levy and Murnane 2004). High information-intensity and high-skill occupations are less amenable to rule-based logic because they require the ability to formulate and solve new and unanticipated problems, design and create new products and services, exercise judgment in the face of uncertainty, and manage others. These occupations involve the use of tacit contextual knowledge and thought processes to recognize complex patterns and apply case-based reasoning (Levy and Murnane 2004). In summary, high informationintensity and high-skill occupations are less amenable to offshoring because of the difficulty of codifying, standardizing, and modularizing the activities that require rapid decision making and exception handling. Thus,

Hypothesis 3. The skill level of an occupation (a) is negatively associated with codifiability, standardizability, modularizability, and disaggregation potential and (b) negatively moderates the effect of information intensity on codifiability, standardizability, modularizability, and disaggregation potential.

\subsection{The Need for Physical Presence and Service Disaggregation}

A distinguishing feature of services is the need for customer contact in service processes, which intro- duces variability in service outcomes (Parasuraman et al. 1988). The contact theory of service processes provides a theoretical lens through which to analyze service processes in terms of their potential for service disaggregation. In an early study on contact theory, Chase (1981) proposes a classification of services in terms of decreasing customer contact-pure services, mixed services, and quasimanufacturing services. Pure services require physical presence and face-to-face contact with a customer, whereas quasimanufacturing services require virtually no face-toface contact. Mixed services have a mix of face-to-face contact and loosely coupled back-office work that can be performed remotely.

Typically, pure services comprise occupations that deal with the manipulation of physical objects that require physical presence and must be performed within specific space and time constraints (Apte and Mason 1995). In some services, physical manipulation requires social interactions and communication that are difficult to accomplish remotely. For example, the requirements-definition phase in software development requires interactions and transmission of information among many stakeholders, and ensuring effective communication among distributed team members remains a big challenge (Ramasubbu et al. 2007). In a review of research on computer-supported cooperative work, Olson and Olson observe that

reports of distance's death are exaggerated. Even with all our emerging information and communications technologies, distance and its associated attributes of culture, time zone, geography and language affect how humans interact with each other. There are characteristics of face-to-face interactions, particularly the space/time contexts in which such interactions take place, which the emerging technologies are either pragmatically or logically incapable of replicating.... Distance is not only alive and well, it is in several essential respects immortal. (2000, pp. 140-41)

The importance of physical presence is evident in many sectors throughout the economy. A McKinsey study (McKinsey Global Institute 2003) estimates that $70 \%$ of the U.S. economy consists of locally produced and consumed services that require physical proximity. Drezner (2004) estimates U.S. jobs that require proximity even higher, at $90 \%$. Researchers note that jobs that require proximity are less likely candidates for disaggregation (Bryson 2001, May 
2002). Thus, we expect that occupations with a higher need for physical presence will be less susceptible to disaggregation pressures than occupations with a lower need for physical presence, which can be more easily disaggregated.

Hypothesis 4. Occupations with a higher need for physical presence have lower disaggregation potential than occupations with a lower need for physical presence.

We control for the need for customer contact, which has some overlap with the concepts of information intensity and the need for physical presence. Kellogg and Chase (1995) describe three dimensions of customer contact: coupling, interdependence, and information richness. Coupling is the extent to which the customer and service provider affect each other during the service interaction. Interdependence is the extent to which the service provider directly controls the service outcome (Victor 1990). Information richness is the value of information exchanged between the customer and the service provider (Daft and Lengel 1984). These three dimensions link directly to Apte and Mason's (1995) discussion of customer contact, which consists of both the in-person contact required to create a service (coupling and interdependence) and the symbolic contact (information richness) to exchange information necessary for service creation.

\section{Method}

\subsection{Data}

A methodological strength of this study is the use of data from separate sources to answer our research questions, thus avoiding common method bias. We began with the list of 140 service occupations that Apte and Mason (1995) derive from the 1990 Standard Occupational Classification (SOC) codes. We mapped each of these service occupation titles to the 1999 SOC codes maintained by the U.S. Department of Labor Bureau of Labor Statistics (BLS). Because these 140 occupation categories included some residual and summary categories and because our econometric analyses require a consistent unit of analysis, we removed the residual categories and identified the detailed SOC categories underlying the summary categories. This process resulted in 332 observations at the same unit of analysis (detail occupation level).
We created three protocols ${ }^{5}$ to measure and assess the reliability of the three sets of variables: (1) a protocol for the coding of the information-intensity, needfor-physical-presence, and need-for-customer-contact variables (author coding to validate reliability of Apte and Mason's 1995 coding); (2) a protocol for codifiability, standardizability, and modularizability (author coding and verification from independent coders); and (3) a protocol for perceived disaggregation potential (to gather primary data from independent coders). We used prior literature to inform the development of the protocols, and we refined the protocols through a process of iteration to improve the content, wording, and ease of comprehension.

For the information-intensity, need-for-physicalpresence, and need-for-customer-contact variables, we used Apte and Mason's (1995) coding, which is of high quality because they conducted a significant amount of related research and had the necessary expertise to code these variables. Nevertheless, we performed a reliability check by coding $10 \%$ of the occupations ourselves. Because previous studies have pointed to limitations of reliability measures, such as the Kappa measure (Brennan and Prediger 1981, Perreault and Leigh 1989), for settings in which marginals are free and not fixed a priori (a situation that applies in our setting), we use the proportional reduction in loss (PRL) measure of reliability (Rust and Cooil 1994). The PRL measure is more general than many other measures and is based on a theory of decision-making loss that relates reliability to loss from poor decisions (Rust and Cooil 1994). ${ }^{6}$ We calculated scaled percentage agreement among judges, as Cohen (1968) suggests. On the basis of these values of percentage agreement, we obtained PRL values of $0.95,0.93$, and 0.94 for information intensity, need for physical presence, and need for customer contact, respectively, these results indicate that Apte and Mason's coding is reliable.

For codifiability, standardizability, and modularizability, one of the authors coded these variables

\footnotetext{
${ }^{5}$ For details, see Appendix A; Appendixes A and B are contained in an online supplement to this paper that is available on the Information Systems Research website (http://isr.pubs.informs.org/ ecompanion.html).

${ }^{6}$ For a detailed discussion of the advantages of PRL over other reliability measures, see Rust and Cooil (1994).
} 
following a standard protocol. To assess reliability, we engaged two independent coders to code $20 \%$ of the occupations for codifiability, standardizability, and modularizability. Both independent coders were doctoral students with at least five years of professional work experience and master's degrees, and they were unaware of this study's purpose and specific hypotheses. We assessed the reliability of codifiability, standardizability, and modularizability using the PRL measure and found that these variables were of acceptable quality (PRL values of 0.92 for codifiability, 0.93 for standardizability, and 0.91 for modularizability).

For disaggregation potential, two practicing managers, who were unaware of this study's purpose and specific hypotheses, performed the coding. One coder works for Infosys (a major offshoring firm), and the other coder works for HP Labs India (a major multinational firm with an offshore base in India). Both coders have Ph.D.s and are active researchers. We assessed the interrater reliability of their coding by comparing it with that of Apte and Mason (1995) and obtained a PRL value of 0.94 . In our empirical analysis, we used an average of the coding from the two practicing managers for disaggregation potential. Finally, we used data on the skill level of occupations from the U.S. Occupational Projections and Training Data (2004-2005 edition). After we combined data from all sources, there were 322 observations for which we had data on all variables.

Table 2 provides a summary of variable definitions and sources. Table 3 provides descriptive statistics and zero-order correlations for our model variables. Information intensity is positively correlated with the skill level of an occupation (0.63), indicating that a higher percentage of workers in high informationintensity occupations have a college degree. The need for physical presence and for customer contact are positively correlated (0.67), suggesting that many occupations that require physical presence also require customer contact. Perceived disaggregation potential is positively correlated with information intensity (0.55) and negatively correlated with the need for physical presence (-0.72). As might be expected, codifiability and standardizability have a strong positive correlation (0.91) because the codifiability of activities in an occupation also facilitates standardizability in that occupation. The negative correlations between modularizability and the need for physical presence $(-0.39)$ and between modularizability and the need for customer contact $(-0.48)$ indicate that occupations with greater needs for physical presence and customer contact may be less modularizable. The positive correlation between modularizability and perceived disaggregation potential (0.52) implies that more modularizable occupations are more amenable to service disaggregation. Overall, these correlations are consistent with the arguments in the theory section.

\subsection{Empirical Models and Econometric Issues}

We specify standard cross-sectional models of the form

$$
Y_{i}=X_{i} \beta+\varepsilon_{i},
$$

where $Y$ represents endogenous variables, such as perceived disaggregation potential, codifiability, standardizability, and modularizability; $X$ represents a vector of occupational characteristics, such as information intensity, skill level, the need for physical presence, and the need for customer contact; $\beta$ s are the parameters to be estimated; and $\varepsilon$ is the error term associated with occupation $i$.

We use ordinary least squares (OLS) to estimate our models. ${ }^{7}$ Because our system of equations represents a recursive model, OLS provides consistent and efficient estimates. Although the need for physical presence and for customer contact are highly correlated, we retain both variables in our econometric models because they are conceptually distinct. Furthermore, from an econometric perspective, dropping a variable will lead to omitted variable bias if that variable actually belongs in the model. Meanwhile, retaining a redundant variable in the model that is correlated with some other independent variable(s) only hampers our ability to parse out the independent effect of that variable. We tested for multicollinearity, and the highest variance inflation factor value of 6.03 suggests that multicollinearity is not a serious concern

\footnotetext{
${ }^{7}$ Because values for the dependent variable disaggregation potential range only from 1 to 3 , we checked the robustness of our OLS models by using ordered probit models (see Appendix B in the online supplement). The ordered probit results are similar to the OLS results. For simplicity, we report OLS results for all our models.
} 
Table 2 Variables and Data Sources

\begin{tabular}{|c|c|}
\hline Variable name & Definition and operationalization \\
\hline $\begin{array}{l}\text { Perceived disaggregation } \\
\text { potential }\end{array}$ & $\begin{array}{l}\text { Describes the extent to which an occupation can be globally disaggregated. Apte and Mason (1995) evaluate the perceived } \\
\text { disaggregation potential of each occupation as low, medium, or high. For this paper, numerical scores for Apte and } \\
\text { Mason's ordinal scheme are } 1=\text { low, } 2=\text { medium, and } 3=\text { high. } \\
\text { Source: Coding by independent practicing managers; interrater reliability }=0.94 \text {. }\end{array}$ \\
\hline Information intensity & $\begin{array}{l}\text { Defined as the ratio of time spent dealing with information to the total time spent in an activity. } \\
\text { Source: Adapted from Apte and Mason (1995); interrater reliability }=0.95 \text {. }\end{array}$ \\
\hline Need for physical presence & $\begin{array}{l}\text { Defined as the ratio of time spent in physical actions to the total time spent in an activity. } \\
\text { Source: Adapted from Apte and Mason (1995); interrater reliability }=0.93 \text {. }\end{array}$ \\
\hline Codifiability & $\begin{array}{l}\text { The extent to which the activities in an occupation can be described completely in a set of written instructions. Occupations } \\
\text { with a high proportion of explicit knowledge are more codifiable than occupations that use tacit knowledge. } \\
\text { Source: Author coding; interrater reliability }=0.92 \text {. }\end{array}$ \\
\hline Standardizability & $\begin{array}{l}\text { The extent to which the activities in an occupation can be performed successfully using a set of consistent and repeatable } \\
\text { processes. The consistency of processes applies across different workers and across different cases. } \\
\text { Source: Author coding; interrater reliability }=0.93 \text {. }\end{array}$ \\
\hline Modularizability & $\begin{array}{l}\text { The extent to which the activities in an occupation can be separated into components so that the components can be } \\
\text { performed independently by separate people and then be integrated. } \\
\text { Source: Author coding; interrater reliability }=0.91 \text {. }\end{array}$ \\
\hline Skill level & $\begin{array}{l}\text { Indicates the skill required for an occupation; it is measured by percentage of employees in the occupation } \\
\text { holding a college degree. } \\
\text { Source: Occupational Projections and Training Data 2004-2005. }\end{array}$ \\
\hline Need for customer contact & $\begin{array}{l}\text { Defined as the ratio of time during which a customer is in direct contact with the service facility to the total time } \\
\text { required for creation of the service. } \\
\text { Source: Adapted from Apte and Mason (1995); interrater reliability }=0.94 \text {. }\end{array}$ \\
\hline Employment growth & $\begin{array}{l}\text { Indicates the growth in employment level of an occupation from one year to another. For each occupation, employment } \\
\text { growth is computed as ([employment level in the end year - employment level in beginning year]/[employment level } \\
\text { in the beginning year]). EMPGRO }{ }_{99-00} \text { refers to employment growth from } 1999 \text { to } 2000 \text { with } 1999 \text { as a base year, } \\
\text { and EMPGRO } \\
\text { Sources } \text { refers to employment growth from } 2000 \text { to } 2004 \text { with } 2000 \text { as a base year. }\end{array}$ \\
\hline Salary growth & $\begin{array}{l}\text { Indicates the growth in the average salary of an occupation from one year to another, after deflating nominal salary } \\
\text { levels to real } 1998 \text { dollars by using the U.S. consumer price index. For each occupation, salary growth is computed } \\
\text { as ([average salary in the end year - average salary in the beginning year]/[average salary in the beginning year]). } \\
\text { SALGRO }_{99-00} \text { refers to salary growth from } 1999 \text { to } 2000 \text { with } 1999 \text { as a base year, and SALGRO } 0_{00-04} \text { refers to salary } \\
\text { growth from } 2000 \text { to } 2004 \text { with } 2000 \text { as a base year. } \\
\text { Source: OES data } 1999-2004 \text {. }\end{array}$ \\
\hline
\end{tabular}

in our analyses. ${ }^{8}$ We accounted for heteroskedastic error distribution and calculated heteroskedasticityconsistent standard errors for all our models.

\section{Results and Discussion}

\subsection{Testing the Theory of Service Disaggregation}

Column 1 of Table 4 presents the results of Equation (1); it does not include the mediating mechanisms of codifiability, standardizability, and modularizability. Consistent with Hypothesis 1, we find that at

${ }^{8}$ An implication of this result is that despite the high correlation between the need for physical presence and the need for customer contact, we can detect their individual effects in our models. the mean value of skill level, information intensity has a positive, statistically significant association (coefficient $=0.191, p<0.001$ ) with perceived disaggregation potential.

Hypotheses 2(a), 2(b), and 2(c) predict that the effects of information intensity on disaggregation potential will be mediated by codifiability, standardizability, and modularizability, respectively. To test these hypotheses, we performed mediation analysis using the Sobel tests (Baron and Kenny 1986, Sobel 1982). ${ }^{9}$ We do not find support for Hypotheses 2(a) or 2(b), but we find support for Hypothesis 2(c).

${ }^{9}$ Appendix B in the online supplement shows detailed results of the Sobel tests. 
Mithas and Whitaker: Is the World Flat or Spiky?

Table 3 Descriptive Statistics and Correlations $(N=322)$

\begin{tabular}{|c|c|c|c|c|c|c|c|c|c|c|c|c|}
\hline & 1 & 2 & 3 & 4 & 5 & 6 & 7 & 8 & 9 & 10 & 11 & 12 \\
\hline Salary growth $_{00-04}$ & 1.00 & & & & & & & & & & & \\
\hline Employment growth $_{00-04}$ & -0.08 & 1.00 & & & & & & & & & & \\
\hline Perceived disaggregation potential & 0.14 & -0.17 & 1.00 & & & & & & & & & \\
\hline Information intensity & 0.20 & -0.03 & 0.55 & 1.00 & & & & & & & & \\
\hline Need for customer contact & -0.11 & 0.17 & -0.53 & -0.24 & 1.00 & & & & & & & \\
\hline Need for physical presence & -0.24 & 0.23 & -0.72 & -0.47 & 0.67 & 1.00 & & & & & & \\
\hline Employment growth $_{99-00}$ & -0.06 & 0.21 & 0.01 & 0.05 & -0.02 & -0.01 & 1.00 & & & & & \\
\hline Salary growth $_{99-00}$ & -0.15 & 0.06 & 0.05 & 0.12 & -0.05 & -0.02 & -0.01 & 1.00 & & & & \\
\hline Codifiability & -0.27 & -0.10 & 0.13 & -0.27 & -0.15 & -0.06 & 0.11 & -0.03 & 1.00 & & & \\
\hline Standardizability & -0.28 & -0.11 & 0.11 & -0.29 & -0.16 & -0.05 & 0.06 & -0.03 & 0.91 & 1.00 & & \\
\hline Modularizability & -0.05 & -0.13 & 0.52 & 0.28 & -0.48 & -0.39 & 0.09 & -0.02 & 0.34 & 0.31 & 1.00 & \\
\hline Skill level & 0.23 & 0.17 & 0.22 & 0.63 & -0.06 & -0.16 & 0.08 & 0.04 & -0.43 & -0.46 & 0.02 & 1.00 \\
\hline M & 3.34 & 4.32 & 1.77 & 2.32 & 2.29 & 2.29 & 3.34 & 1.88 & 2.53 & 2.52 & 2.11 & 47.71 \\
\hline SD & 5.82 & 20.29 & 0.75 & 0.84 & 0.89 & 0.88 & 12.45 & 4.42 & 0.61 & 0.64 & 0.79 & 32.68 \\
\hline Minimum & -13.30 & -60.72 & 1 & 1 & 1 & 1 & -53.91 & -12.28 & 1 & 1 & 1 & 0.60 \\
\hline Maximum & 25.52 & 88.45 & 3 & 3 & 3 & 3 & 67.78 & 25.06 & 3 & 3 & 3 & 99.4 \\
\hline
\end{tabular}

Note. All correlations equal to or greater than 0.11 are statistically significant at $p<0.05$.

Table 4 Parameter Estimates

\begin{tabular}{|c|c|c|c|c|c|c|c|}
\hline & $\begin{array}{c}(1) \\
\text { Perceived } \\
\text { disaggregation } \\
\text { potential }\end{array}$ & Codifiability & Standardizability & Modularizability & $\begin{array}{c}(5) \\
\text { Perceived } \\
\text { disaggregation } \\
\text { potential }\end{array}$ & $\begin{array}{c}\text { (6) } \\
\text { Employment } \\
\text { growth }_{00-04}\end{array}$ & $\begin{array}{c}\text { (7) } \\
\text { Salary } \\
\text { growth } \\
00-04\end{array}$ \\
\hline Information intensity & $\begin{array}{l}0.191^{* * *} \\
(0.000)\end{array}$ & $\begin{array}{c}-0.028 \\
(0.660)\end{array}$ & $\begin{array}{r}-0.015 \\
(0.806)\end{array}$ & $\begin{array}{l}0.223^{* * *} \\
(0.001)\end{array}$ & $\begin{array}{l}0.151^{* * *} \\
(0.004)\end{array}$ & $\begin{array}{c}1.515 \\
(0.354)\end{array}$ & $\begin{array}{r}-0.840 \\
(0.157)\end{array}$ \\
\hline Codifiability & & & & & $\begin{array}{c}0.081 \\
(0.312)\end{array}$ & & \\
\hline Standardizability & & & & & $\begin{array}{l}0.064 \\
(0.398)\end{array}$ & & \\
\hline Modularizability & & & & & $\begin{array}{l}0.195^{* * *} \\
(0.000)\end{array}$ & & \\
\hline Skill level & $\begin{array}{r}-0.021 \\
(0.612)\end{array}$ & $\begin{array}{l}-0.258^{* * *} \\
(0.000)\end{array}$ & $\begin{array}{l}-0.299 * * * \\
(0.000)\end{array}$ & $\begin{array}{l}-0.142^{* * *} \\
(0.008)\end{array}$ & $\begin{array}{c}0.046 \\
(0.301)\end{array}$ & $\begin{array}{l}2.802^{* *} \\
(0.037)\end{array}$ & $\begin{array}{l}1.722^{* * *} \\
(0.000)\end{array}$ \\
\hline $\begin{array}{l}\text { Information intensity } \\
\quad \times \text { skill level }\end{array}$ & $\begin{array}{c}-0.093^{* *} \\
(0.018)\end{array}$ & $\begin{array}{c}0.034 \\
(0.521)\end{array}$ & $\begin{array}{c}0.051 \\
(0.329)\end{array}$ & $\begin{array}{c}-0.008 \\
(0.884)\end{array}$ & $\begin{array}{c}-0.098^{* *} \\
(0.020)\end{array}$ & $\begin{array}{l}4.548^{* * *} \\
(0.002)\end{array}$ & $\begin{array}{c}-1.060^{* *} \\
(0.026)\end{array}$ \\
\hline $\begin{array}{l}\text { Need for physical } \\
\text { presence }\end{array}$ & $\begin{array}{l}-0.351^{* * *} \\
(0.000)\end{array}$ & $\begin{array}{c}-0.039 \\
(0.385)\end{array}$ & $\begin{array}{r}-0.029 \\
(0.524)\end{array}$ & $\begin{array}{r}-0.003 \\
(0.957)\end{array}$ & $\begin{array}{l}-0.345^{* * *} \\
(0.000)\end{array}$ & $\begin{array}{l}3.951^{* *} \\
(0.010)\end{array}$ & $\begin{array}{l}-1.391^{* * *} \\
(0.005)\end{array}$ \\
\hline $\begin{array}{l}\text { Need for customer } \\
\text { contact }\end{array}$ & $\begin{array}{c}-0.113^{* * *} \\
(0.005)\end{array}$ & $\begin{array}{c}-0.090^{* *} \\
(0.021)\end{array}$ & $\begin{array}{l}-0.106^{* * *} \\
(0.007)\end{array}$ & $\begin{array}{l}-0.332^{* * *} \\
(0.000)\end{array}$ & $\begin{array}{c}-0.035 \\
(0.426)\end{array}$ & $\begin{array}{l}1.251 \\
(0.345)\end{array}$ & $\begin{array}{c}0.187 \\
(0.642)\end{array}$ \\
\hline $\begin{array}{l}\text { Employment } \\
\text { growth }_{99-00}\end{array}$ & & & & & & $\begin{array}{c}0.310^{* *} \\
(0.020)\end{array}$ & \\
\hline Salary growth ${ }_{99-00}$ & & & & & & & $\begin{array}{c}-0.207^{* *} \\
(0.013)\end{array}$ \\
\hline Constant & $\begin{array}{l}1.834^{* * *} \\
(0.000)\end{array}$ & $\begin{array}{l}2.506^{* * *} \\
(0.000)\end{array}$ & $\begin{array}{l}2.492^{* * *} \\
(0.000)\end{array}$ & $\begin{array}{l}2.120^{* * *} \\
(0.000)\end{array}$ & $\begin{array}{l}1.059^{* * *} \\
(0.000)\end{array}$ & $\begin{array}{c}0.426 \\
(0.758)\end{array}$ & $\begin{array}{l}4.396^{* * *} \\
(0.000)\end{array}$ \\
\hline Observations & 322 & 322 & 322 & 322 & 322 & 322 & 322 \\
\hline$R$-square & 0.593 & 0.226 & 0.255 & 0.282 & 0.646 & 0.156 & 0.140 \\
\hline
\end{tabular}

Notes. We use standardized values of information intensity, the need for physical presence, the need for customer contact, and skill level in these models for easier interpretation of the results. Robust $p$ values are in parentheses. ${ }^{* *}$ Significant at $5 \% ;{ }^{* * *}$ significant at $1 \%$. 
As Columns 2-4 of Table 4 show, although information intensity does not have a statistically significant association with codifiability or standardizability, it has a positive, statistically significant association with modularizability (coefficient $=0.223, p<$ 0.001 ) at the mean value of skill level. An explanation for this result may be that many high informationintensity occupations also require higher skill levels, which makes these occupations less codifiable and standardizable, even though some tasks can be encapsulated in modules.

We tested for the extent of mediation by including codifiability, standardizability, and modularizability variables in the perceived disaggregation potential model (Column 5, Table 4). A reduction in the coefficient of information intensity (coefficient $=0.151, p<$ 0.004 ) at the mean value of skill level when we control for codifiability, standardizability, and modularizability suggests that the association of information intensity with perceived disaggregation potential is partially mediated through modularizability. Overall, these results provide partial support for the mediation hypotheses. They also suggest that information intensity has a direct association with perceived disaggregation potential or that there are other mediating mechanisms besides codifiability, standardizability, and modularizability.

Because of the high correlation between codifiability and standardizability, we also conducted our analyses by entering codifiability, standardizability, and modularizability sequentially and in pairs. Table 5 presents these results. Columns 1-3 of Table 5 show that each of the variables-codifiability, standardizability, and modularizability-has a positive association with perceived disaggregation potential when considered in isolation, as discussed in \$2. Column 4 shows that only codifiability remains statistically significant when standardizability is also included in the model. Columns 5 and 6 show that modularizability is positively associated with perceived disaggregation potential in the models that include either codifiability or standardizability, and in these models, the coefficients of codifiability and standardizability are statistically significant. Together, the results in Columns 4-6 provide some evidence for the argument that codifiability and standardizability are important

Table 5 Robustness Check for Mediating Models

\begin{tabular}{|c|c|c|c|c|c|c|}
\hline & \multicolumn{6}{|c|}{ Dependent variable: Perceived disaggregation potential } \\
\hline & (1) & $(2)$ & (3) & $(4)$ & (5) & (6) \\
\hline Information intensity & $\begin{array}{l}0.198^{* * *} \\
(0.000)\end{array}$ & $\begin{array}{l}0.194^{* * *} \\
(0.000)\end{array}$ & $\begin{array}{l}0.139 * * * \\
(0.007)\end{array}$ & $\begin{array}{l}0.197^{* * *} \\
(0.000)\end{array}$ & $\begin{array}{l}0.152^{* * *} \\
(0.003)\end{array}$ & $\begin{array}{l}0.149 * * * \\
(0.004)\end{array}$ \\
\hline Codifiability & $\begin{array}{l}0.227^{* * *} \\
(0.000)\end{array}$ & & & $\begin{array}{l}0.164^{* *} \\
(0.039)\end{array}$ & $\begin{array}{l}0.139^{* *} \\
(0.011)\end{array}$ & \\
\hline Standardizability & & $\begin{array}{l}0.208^{* * *} \\
(0.000)\end{array}$ & & $\begin{array}{c}0.069 \\
(0.359)\end{array}$ & & $\begin{array}{l}0.130^{* *} \\
(0.011)\end{array}$ \\
\hline Modularizability & & & $\begin{array}{l}0.235^{* * *} \\
(0.000)\end{array}$ & & $\begin{array}{l}0.195^{* * *} \\
(0.000)\end{array}$ & $\begin{array}{l}0.200^{* * *} \\
(0.000)\end{array}$ \\
\hline Skill level & $\begin{array}{c}0.037 \\
(0.392)\end{array}$ & $\begin{array}{c}0.041 \\
(0.355)\end{array}$ & $\begin{array}{c}0.012 \\
(0.777)\end{array}$ & $\begin{array}{c}0.042 \\
(0.347)\end{array}$ & $\begin{array}{c}0.042 \\
(0.334)\end{array}$ & $\begin{array}{c}0.046 \\
(0.303)\end{array}$ \\
\hline $\begin{array}{l}\text { Information intensity } \\
\times \text { skill level }\end{array}$ & $\begin{array}{l}-0.101^{* *} \\
(0.014)\end{array}$ & $\begin{array}{l}-0.104^{* *} \\
(0.012)\end{array}$ & $\begin{array}{c}-0.092^{* *} \\
(0.026)\end{array}$ & $\begin{array}{c}-0.103^{* *} \\
(0.014)\end{array}$ & $\begin{array}{c}-0.097^{* *} \\
(0.021)\end{array}$ & $\begin{array}{c}-0.099^{* *} \\
(0.019)\end{array}$ \\
\hline $\begin{array}{l}\text { Need for physical } \\
\text { presence }\end{array}$ & $\begin{array}{l}-0.342^{* * *} \\
(0.000)\end{array}$ & $\begin{array}{l}-0.345^{* * *} \\
(0.000)\end{array}$ & $\begin{array}{c}-0.350^{* * *} \\
(0.000)\end{array}$ & $\begin{array}{l}-0.343^{* * *} \\
(0.000)\end{array}$ & $\begin{array}{l}-0.345^{* * *} \\
(0.000)\end{array}$ & $\begin{array}{l}-0.347^{* * *} \\
(0.000)\end{array}$ \\
\hline $\begin{array}{l}\text { Need for customer } \\
\text { contact }\end{array}$ & $\begin{array}{c}-0.093^{* *} \\
(0.025)\end{array}$ & $\begin{array}{c}-0.091^{* *} \\
(0.027)\end{array}$ & $\begin{array}{l}-0.035 \\
(0.405)\end{array}$ & $\begin{array}{c}-0.091^{* *} \\
(0.028)\end{array}$ & $\begin{array}{c}-0.036 \\
(0.406)\end{array}$ & $\begin{array}{c}-0.033 \\
(0.445)\end{array}$ \\
\hline Constant & $\begin{array}{l}1.264^{* * *} \\
(0.000)\end{array}$ & $\begin{array}{l}1.314^{* * * *} \\
(0.000)\end{array}$ & $\begin{array}{l}1.335^{* * *} \\
(0.000)\end{array}$ & $\begin{array}{l}1.251^{* * *} \\
(0.000)\end{array}$ & $\begin{array}{l}1.072^{* * * *} \\
(0.000)\end{array}$ & $\begin{array}{l}1.084^{* * *} \\
(0.000)\end{array}$ \\
\hline Observations & 322 & 322 & 322 & 322 & 322 & 322 \\
\hline$R$-square & 0.619 & 0.617 & 0.637 & 0.620 & 0.646 & 0.646 \\
\hline
\end{tabular}

Notes. We use standardized values of information intensity, need for physical presence, need for customer contact need, and skill level in these models for easier interpretation of the results. Robust $p$ values are in parentheses. ${ }^{* *}$ Significant at $5 \%$; ${ }^{* * *}$ significant at $1 \%$. 
determinants of perceived disaggregation potential, even though codifiability and standardizability lose their significance when modularizability is included in the model. ${ }^{10}$

We find mixed support for Hypotheses 3(a) and $3(\mathrm{~b})$ regarding the role of occupational skill level. As Hypothesis 3(a) predicted, at the mean value of information intensity, skill level is negatively associated with codifiability, standardizability, and modularizability. Furthermore, as Hypothesis 3(b) predicted, skill level moderates the effect of information intensity on perceived disaggregation potential. However, we do not find either a direct effect of skill on perceived disaggregation potential or a moderating effect of skill on the relationship between information intensity and codifiability, standardizability, and modularizability. Overall, these results provide some support for the reasoning that underlies Hypotheses 3(a) and $3(b)$.

Consistent with Hypothesis 4, we find that the need for physical presence has a negative, statistically significant association (coefficient $=-0.351, p<0.000$ ) with perceived disaggregation potential. Among control variables, we find that the need for customer contact has a negative association with codifiability, standardizability, modularizability, and perceived disaggregation potential.

To summarize our results in this section, consistent with our expectations, we find a positive association between information intensity and perceived disaggregation potential and a negative association between the need for physical presence and perceived disaggregation potential. Although both codifiability and standardizability are associated with perceived disaggregation potential, we do not find support for the codifiability- and standardizabilitymediated effect of information intensity on disaggregation potential. We also find evidence for the negative effect of skills on codifiability, standardizability, and modularizability and moderating effect of skills on the relationship between information intensity and disaggregation potential. Overall, these results provide broad support for the theory of service disaggregation.

${ }^{10}$ We report additional robustness checks and sensitivity analyses in Appendix B in the online supplement.

\subsection{How Information Intensity and Skills Influence Employment and Salary Growth}

Although employment and salary growth are not perfect measures of actual service disaggregation, previous research in the IS and economics literature argues that these indirect measures can be useful in understanding how occupational attributes may affect actual global service disaggregation (i.e., offshoring). For example, Hirschheim et al. (2005, p. 1004) note, "In the absence of official statistics on offshoring, it is necessary to look at indirect measures, such as trade in services and employment data." Venkatraman (2004, p. 14) notes,

At the heart of the debate is the issue of jobs and wages.... Offshoring has put downward pressure on domestic salaries;... we seem to be emerging from the current recession with no net increase in professional higher-wage jobs, because many of these have migrated overseas.

Therefore, to the extent that offshoring is associated with changes in U.S. employment and salaries, we study how occupations have fared in terms of employment and salary growth as a function of their intrinsic occupational characteristics. Because IT is a catalyst for service disaggregation and service disaggregation is partly manifest in the offshoring of services (a new form of international trade), we now draw on the economics literature that relates international trade and IT to employment and salary growth.

International trade theory suggests that under certain conditions, ${ }^{11}$ international trade will lead to an increase in wages for the abundant factor (in the United States, skilled labor) and a reduction in wages for the scarce factor (unskilled labor) (for a review, see Deardorff and Hakura 1994). There appears to be some consensus that even if international trade is not the primary cause of these changes to wages and employment, international trade has had at least a measurable impact on the relative wages and employment of U.S. skilled and unskilled workers (Baily and Lawrence 2004, Deardorff 2000, Krugman 2000, Richardson 1995, Slaughter 1998).

In contrast with the international trade literature, the labor economics literature focuses on skill-biased

${ }^{11}$ For example, this model assumes that trade has no effect on the aggregate number of jobs and that labor can easily move across industries. 
technical change (SBTC) and argues that instead of international trade, the use of computers and other advanced technologies has increased both demand and wages for skilled labor (Berman et al. 1998, Lawrence and Slaughter 1993, Levy and Murnane 1992, Machin and Van Reenen 1998). Some researchers have noted that these explanations based on "trade" and "technology" are not mutually exclusive. For example, on the basis of his review of the international trade and labor economics literature, Feenstra concludes,

The position of low-skilled workers in the industrial countries is worsened by the complementary combination of globalization and new technology. ... From the perspective of the scarce factor in each country (that is, unskilled labor in the United States),... their wages would be lowered by outsourcing, over and above the impact of trade in final goods. (1998, pp. 47-48)

International trade and IT can affect the employment and wages of U.S. occupations through three mechanisms: (1) a substitution effect (a negative effect on U.S. employment and wage growth if foreign workers are substituted for U.S. employees), (2) a productivity effect (a negative effect if disaggregation enables U.S. firms to become more productive and produce more with fewer U.S. employees), and (3) an insourcing effect (a positive effect if disaggregation enables U.S. firms to become more competitive and increases demand for their products in international markets, leading to more demand for labor in the United States) (Amiti and Wei 2005). Therefore, the overall effect of service disaggregation on U.S. employment and wage growth depends on the net effects from substitution, productivity, and insourcing. Because higher information-intensity occupations are more subject to global disaggregation (see Hypothesis 1), we argue that employment and salary growth of these occupations are more vulnerable to the effects of service disaggregation than are those of lower information-intensity occupations. For example, Rodrik (1997) notes that international trade makes demand for labor more elastic and puts downward pressure on wages by reducing the bargaining power of labor through the perceived threat of offshoring. Because occupations with a higher need for physical presence are less subject to global disaggregation (see Hypothesis 4), we argue that employment and salary growth of such occupations are less vulnerable to effects of service disaggregation than are those of occupations with a lower need for physical presence. For example, May $(2002$, p. 330) notes that personal services that require proximity for delivery "may be the jobs that are safest at the centre of the information economy."

We collected employment and salary data from the OES survey conducted by the BLS. Because the service disaggregation (offshoring) phenomenon began growing in 2000 (Carmel and Agarwal 2002, Hayward 2004), we collected data on trends in U.S. occupations from 1999 to $2004 .{ }^{12}$ We capture heterogeneity across occupations by including 1999-2000 employment and salary growth as a control in our employment and salary growth models, respectively. The inclusion of occupational skill level in these models accounts for the SBTC explanation of employment and salary growth (Autor et al. 1998, Baldwin and Cain 2000, Machin and Van Reenen 1998). Because macroeconomic factors that are invariant across all occupations (e.g., gross domestic product and inflation rate) do not affect our statistical results, we do not include those macroeconomic factors in our analyses. Furthermore, to the extent that these factors are uncorrelated with the independent variables in our study, the results remain robust because these extraneous factors are likely to affect only the error term, not the parameter estimates that are of primary interest in this study. ${ }^{13}$

Columns 6 and 7 of Table 4 show the results of employment growth and salary growth from 2000 to 2004 as dependent variables. We do not find a statistically significant association between information intensity and employment growth or salary growth at the mean level of skill. However, above the mean level of skill, information intensity is associated with higher employment growth but lower salary growth.

\footnotetext{
${ }^{12}$ The authors acknowledge that future studies using data over a longer period will be informative and provide a validation check for these results.

${ }^{13}$ Note that our focal independent variables (information intensity and the need for physical presence) do not change for an occupation in the study period. Thus, we avoid a potential confound that would have presented itself if any omitted variable were correlated with both an occupation attribute and our outcome variables.
} 
The positive association between information intensity and employment growth above the mean level of skill is consistent with the SBTC explanation. Similarly, the negative association between information intensity and salary growth above the mean level of skill is consistent with Rodrik's (1997) argument that international trade makes demand for labor more elastic and puts downward pressure on wages by reducing the bargaining power of workers because of the perceived threat of offshoring. To the extent that the impact of immigration is similar to that of offshoring (e.g., both immigration and offshoring enable firms to substitute foreign labor for local labor), our findings are consistent with previous research that has found a positive relationship between immigration and employment and a negative relationship between immigration and salaries (Friedberg and Hunt 1995). We also find a positive, statistically significant association between the need for physical presence and employment growth and a negative, statistically signficant assocation between the need for physical presence and salary growth.

Our results do not support the popular perception that information-intensive occupations have experienced a decline in employment. Indeed, our analysis suggests that high information-intensive and highskill occupations have actually experienced higher employment growth. An explanation for this finding is that many information-intensive service occupations have a tacit component that may make them difficult to disaggregate in the short run. This is consistent with the theory of service disaggregation presented above and also with standard international trade theory; that is, a country that is abundant in skilled labor will first outsource functions that require relatively lower skills (Stolper and Samuelson 1941). This finding is also similar to the previous experience in manufacturing outsourcing, in which assembly jobs requiring more explicit knowledge were offshored first and design jobs requiring more tacit knowledge remained in the United States (Davis 1999). Outsourcing of services appears to be following a similar pattern; ${ }^{14}$ to date, most services outsourcing has occurred in lower- and moderate-skilled activities, such as

${ }^{14}$ The authors thank an anonymous reviewer for pointing to this rationale. manning call centers, transcribing text or voice, and processing forms (Atkinson 2004). The finding on growth in employment for high information-intensive and high-skill occupations is also supported by recent media reports that suggest that in Silicon Valley, most of the current employment growth is occurring in creative and innovation service occupations, such as $\mathrm{R} \& \mathrm{D}$, scientific and technical consulting, engineering, and design, whereas lower-skill occupations are being moved to lower-cost locations in the United States or offshore (Lewin and Couto 2006, Tam 2006).

Our analysis also suggests that high informationintensive and high-skill occupations have experienced a slight decline in salary growth. These results are supported by recent accounts that offshoring of services is continuing to mature and progress for high-skill services, such as engineering, $R \& D$, and innovation (Baark 1999, Carmel and Agarwal 2002, Engardio et al. 2005, Kishore and Pant 2005, Martin 2006, Prahalad and Krishnan 2004), which in turn may place high information-intensive occupations under some salary pressure, consistent with Rodrik's (1997) previously mentioned argument. ${ }^{15}$

We find that occupations that have a need for physical presence are less likely to be globally disaggregated, though these occupations may be subject to wage pressures caused by the disaggregation of other occupations. Previous research in the manufacturing outsourcing context proposed theoretical models and found empirical support for similar patterns (Feenstra and Hanson 1996, Sachs and Shatz 1996). A recent study by Ward (2006) suggests that more than $80 \%$ of the manufacturing job losses in the U.S. economy since 1990 occurred after 2000, and many people who were laid off from the manufacturing sector sought jobs in the services sector. Ward also finds that many of the new jobs added in the private sector (manufacturing and services) from 2000 to 2005 paid

\footnotetext{
${ }^{15}$ The employment and salary growth of an occupation also depends on factors beyond those suggested by the theory of service disaggregation. For example, financial managers, whose jobs have high disaggregation potential, experienced a negative employment growth of $20.8 \%$ from 2000 to 2004, but they experienced positive salary growth of $15.1 \%$ during the same period, in part because their salaries are typically tied to commissions and stock market performance rather than to "market demand" for the occupation. The authors thank an anonymous reviewer for this example.
} 
significantly less than the new jobs added in previous periods. A recent U.S. government survey also validates this explanation, indicating that $57 \%$ of displaced workers reported earning less than what they earned in their previous job (BLS 2004).

It could be argued that even more than occupational characteristics or SBTC, the growth of the "information economy" during 2000-2004 may explain our results (Apte and Nath 2007). Apte and Nath (2007) estimate the growth in the size of the U.S. information economy for the periods 1967-1992 and 1992-1997. They find that the primary information sector grew faster than the secondary sector during 1967-1992, but the secondary sector grew faster during 1992-1997. ${ }^{16}$ They also find that services constitute $72 \%$ of the primary and secondary information sectors, which suggests a significant correlation between the growth of services and the "information economy." Although Apte and Nath document the correlation between the services sector and the information economy, they do not study the effect of the growth of the information economy on service disaggregation, employment, or wages. Apte and Nath conjecture that "there could have been substantial outsourcing of information activities in the manufacturing industries to outside vendors" (2007, p. 18) within the United States, and they specifically note that this conjecture "needs further investigation" (p. 18).

Our study focuses on services, and we study the implications of information intensity for employment and salary growth at a more granular occupation level. Our findings suggest that service occupations that are more information intensive have a greater likelihood of disaggregation. In turn, this disaggregation is likely to show up in offshoring and changes to employment and salary growth. Thus, Apte and Nath's work at the economy level for the 1992-1997 period does not provide an alternative explanation for

16 "The primary information sector" refers to industries that produce goods and services that convey information or are used to produce, process, or distribute information for an established market. The secondary information sector includes information activities that are produced for internal consumption by government and non-information firms. Examples of primary information sector industries are education, telecommunications, and corporate $R \& D$, and examples of secondary information sector industries are the U.S. federal and state governments. our findings; instead, our study extends their work to the occupation level for the 2000-2004 period.

Overall, these empirical findings support the proposed theory of service disaggregation. They show the usefulness of this theory in understanding observed patterns in the U.S. labor market.

\subsection{Implications}

From a theoretical perspective, this study contributes to an understanding of the global disaggregation of service activities by identifying the factors and mechanisms that make service occupations amenable to global disaggregation, thus extending the work of Apte and Mason (1995) and Rai et al. (2006). We propose a theory of service disaggregation and argue that high information intensity makes an occupation more amenable to disaggregation because the activities in such occupations can be codified, standardized, modularized, and performed in a remote location. This theoretical contribution provides a foundation for a better understanding of service disaggregation and for subsequent research to identify other mediating and moderating mechanisms that may affect the relationship between occupation attributes and service disaggregation. In addition, the use of occupation as a unit of analysis in this research points to a fertile area of research to more fully understand the impact of digital platforms. Studies at the occupation level will augment the understanding of how digital platforms facilitate greater outsourcing and global resource leverage, stronger organizational capabilities, and improved firm performance.

Our findings suggest two important policy and managerial implications. First, from a firm's perspective, occupations with higher information intensity and a lower need for physical presence are the primary candidates for service disaggregation. By making suitable investments in digital platforms to bring an exogenous shift in the information intensity of business processes, managers can decouple information-intensive activities from activities that require physical presence. Our finding that modularizability partially mediates the relationship between information intensity and disaggregation potential calls for firms to focus on process modularization capabilities. Digital enterprises need to develop process expertise so they can evaluate the interdependencies among service activities, modularize the 
activities, disaggregate the activities to take advantage of global resources, and reintegrate outputs from the disaggregated processes into the service activity to provide the customer with a seamless experience. This will enable firms to optimize their portfolio of business processes and to locate the processes where they can be performed with greater effectiveness at a lower cost.

Second, from a policy perspective and the perspective of an individual knowledge worker, our results suggest that despite the amenability of informationintensive occupations to offshoring, on average, high information-intensive occupations have not yet experienced a decline in employment or salary growth. Indeed, high information-intensity occupations have experienced greater salary growth than have occupations with a higher need for physical presence. Moreover, high information-intensity and high-skill occupations have experienced higher employment growth. These results imply that although information -intensive jobs are more likely to be offshored in the long run, there appears to be no current need for protectionist policies specifically designed to avoid migration of information-intensive jobs overseas. From the perspective of U.S. knowledge workers, our study suggests that these workers will benefit by proactively making investments in their human capital through acquiring business and technical skills that will be in demand in the emerging service economy. Knowledge workers must become accustomed to the idea of continuous investment in their skills to make their own employment less vulnerable to disaggregation, even as they search for ways to make their firms more adept at modularizing business processes to take advantage of global resources.

\subsection{Further Research}

First, further research is needed to understand the mix of skills that will be more valuable in the emerging services economy. A recent study suggests that business skills are valued more than technical skills for IT workers in the United States (Mithas and Krishnan 2007); such studies need to be replicated for workers in other professions in other countries as well and need to consider other skills, such as complex communication, expert thinking, and behavioral and customer interaction skills (Hirschheim et al. 2005, Levy and Murnane 2004, Ramasubbu et al. 2007, RussEft 2004). Although research shows complementarities between behavioral and technical skills in terms of customer satisfaction (Ramasubbu et al. 2007) and customer satisfaction as an important antecedent of stock market performance (Fornell et al. 2006), the extent to which firms pay any salary premiums to employees who possess higher levels of both behavioral and technical skills remains unknown. There is also a need for empirical studies to understand the patterns of alignment between human resources practices and IT practices that are most appropriate for managing knowledge workers in the emerging economy. Recent work by Tafti et al. (2007) provides a foundation for undertaking such studies.

Second, the lack of support for mediation results associated with codifiability and standardizability and the patterns of correlations among mediating mechanisms suggest a need to further explore the interlinkages among codifiability, standardizability, and modularizability. Although codifiability and standardizability are conceptually distinct (as we described in $\$ \S 2.1 .1$ and 2.1.2), high correlations among these variables indicate that codifiability may be a necessary condition for standardizability. In other words, it may be difficult for two parties to achieve a set of consistent and repeatable processes (standardizability) if those processes are not first documented in a form that can be understood by both parties (codifiability). At the same time, codifiability and standardizability may not always be necessary conditions for modularizability. For example, there could be situations in which the interfaces between modules are standardized but the activities within modules are not standardized. In such situations, it could be possible to achieve service disaggregation of information-intensive activities without codification and standardization of those activites. ${ }^{17}$ An empirical examination of these conjectures will provide a deeper understanding of the service disaggregation mechanisms.

Third, there is a need to quantify the potential benefits of IT-enabled disaggregation and offshoring at the firm and economy levels. At the firm level, offshoring can enable firms to reduce costs and cycle

\footnotetext{
${ }^{17}$ The authors thank Arun Rai for this explanation.
} 
time dramatically and access professional skills and emerging markets across the globe (Apte and Mason 1995, Carmel and Agarwal 2002). At the economy level, although some observers have expressed concerns about attributing productivity growth to IT (Gordon 2000), others believe that IT-enabled globalization of services could be a precursor to the next wave of productivity growth (Mann 2003). For example, offshoring has the potential to provide economic benefits through the export of medical, educational, or design services (Bhagwati et al. 2004) and the repatriation of earnings, foreign direct investment inflows, and redeployment of labor (Jensen et al. 2006, McKinsey Global Institute 2003). Studying the value of offshoring at the firm and economy levels through IT-enabled changes in occupational composition will provide a more complete understanding of the overall impact of offshoring. Such studies will also extend the business value of IT literature, which to date has focused mainly on the impact of IT expenditures, IT applications, and associated capabilities on firm performance (Brynjolfsson and Hitt 1996; Mithas and Jones 2007; Mithas et al. 2005a, b, 2007; Rai et al. 1997, 2006; Whitaker et al. 2007). ${ }^{18}$

To conclude, we propose a theory of service disaggregation and identify the factors and mechanisms that make service occupations amenable to global disaggregation. Our results suggest that at the mean level of skill, the information intensity of an occupation is positively associated with the disaggregation potential of that occupation, and the effect of information intensity on disaggregation potential is partially mediated by the modularizability of an occupation. We also find that skills moderate the effect of information intensity on service disaggregation. Contrary to popular perception, for the 2000-2004 period, we do not find any adverse effect in terms of employment growth or salary growth for high informationintensity occupations at the mean level of skill. Our findings show that high-skill occupations have experienced higher employment and salary growth than low-skill occupations at the mean level of information intensity. Notably, high information-intensity occupations that require higher skills have experienced

${ }^{18}$ For reviews of business value of IT literature, refer to Barua and Mukhopadhyay (2000), Dedrick et al. (2003), Kauffman and Weill (1989), and Lucas (1993). higher employment growth, though this growth is accompanied by a decline in salary growth. Occupations with a higher need for physical presence have also experienced higher employment growth and lower salary growth. Overall, although these results provide some support for IT as a "flattener," they also point to skills and the need for physical presence as factors that create "spikes" in the global economy. These results have important implications for the improved understanding and management of service processes in digitally enabled global enterprises.

\section{Acknowledgments}

Both authors contributed equally to this paper. The authors thank the ISR special issue senior editors (Arun Rai, Bob Zmud, M. S. Krishnan), Dennis Severance ISR workshop participants, Duke Offshoring conference participants, and three anonymous reviewers for their guidance and helpful comments for improving this manuscript. The authors also thank Ritu Agarwal, Alan Deardorff, Sanjay Gosain, Varun Grover, Kunsoo Han, Rajiv Kohli, Otto Koppius, Frank Levy, Hank Lucas, Narayan Ramasubbu, Pankaj Setia, and seminar participants at the University of Michigan and University of Maryland for their comments on previous versions of this paper. The authors gratefully acknowledge research assistance from Sajeev Cherian, N. Dayasindhu, Prasenjit Dey, Deepak Jain, and Ali Tafti. The first author thanks Pritam Singh and M. P. Jaiswal at the Management Development Institute, Gurgaon, for their kind hospitality during his visit to India in connection with this research. Financial support was provided in part by the Robert $\mathrm{H}$. Smith School of Business and the Center for International Business Education and Research (CIBER) at the University of Maryland, the Stephen M. Ross School of Business at the University of Michigan, and the National Science Foundation (IGERT Grant 0114368).

\section{References}

Amiti, M., S.-J. Wei. 2005. Fear of service outsourcing: Is it justified? Econom. Policy 20(42) 307-347.

Ancori, B., A. Bureth, P. Cohendet. 2000. The economics of knowledge: The debate about codification and tacit knowledge. Indust. Corporate Change 9(2) 255-287.

Andal-Ancion, A., P. A. Cartwright, G. S. Yip. 2003. The digital transformation of traditional businesses. MIT Sloan Management Rev. 44(4) 34-41.

Apte, U. M., R. O. Mason. 1995. Global disaggregation of information-intensive services. Management Sci. 41(7) 1250-1262.

Apte, U. M., H. K. Nath. 2007. The size, structure and growth of the U.S. information economy. U. M. Apte, U. S. Karmarkar, eds. Managing in the Information Economy: Current Research Issue. Springer Science and Business Media, LLC, Norwell, MA, 1-28. 
Argyres, N. S. 1999. The impact of information technology on coordination: Evidence from the B-2 "Stealth" bomber. Organ. Sci. 10(2) 162-180.

Atkinson, R. D. 2004. Understanding the offshore challenge. Policy report, Progressive Policy Institute, Washington, D.C.

Autor, D. H., L. F. Katz, A. B. Krueger. 1998. Computing inequality: Have computers changed the labor market? Quart. J. Econom. 113(4) 1169-1213.

Autor, D. H., F. Levy, R. Murnane. 2003. The skill content of recent technological change: An empirical explanation. Quart. J. Econom. 118(4) 1279-1333.

Baark, E. 1999. Engineering consultancy: An assessment of IT-enabled international delivery of services. Tech. Anal. Strategic Management 11(1) 55-74.

Baily, M. N., R. Z. Lawrence. 2004. What happened to the great U.S. job machine? The role of trade and electronic offshoring (with discussion). Brookings Papers Econom. Activity (2) 211-284.

Baldwin, C. Y., K. B. Clark. 1997. Managing in an age of modularity. Harvard Bus. Rev. 75(5) 84-93.

Baldwin, R. E., G. G. Cain. 2000. Shifts in relative U.S. wages: The role of trade, technology and factor endowments. Rev. Econom. Statist. 82(4) 580-595.

Bardhan, I. R., S. Mithas, S. Lin. 2007. Performance impacts of strategy, information technology applications, and business process outsourcing in US manufacturing plants. Production Oper. Management 16(6).

Bardhan, I. R., J. Whitaker, S. Mithas. 2006. Information technology, production process outsourcing and manufacturing plant performance. J. Management Inform. Systems 23(2) 13-40.

Baron, R. M., D. A. Kenny. 1986. The moderator-mediator variable distinction in social psychological research: Conceptual, strategic, and statistical considerations. J. Personality Soc. Psych. 51(6) 1173-1182.

Bartel, A. P., F. R. Lichtenberg. 1987. The comparative advantage of educated workers in implementing new technology. Rev. Econom. Statist. 69(1) 1-11.

Barua, A., T. Mukhopadhyay. 2000. Information technology and business performance: Past, present, and future. R. W. Zmud, ed. Framing the Domains of Information Technology Management: Projecting the Future... Through the Past. Pinnaflex Press, Cincinnati, OH, 65-84.

Berman, E., J. Bound, Z. Griliches. 1994. Changes in the demand for skilled labor within U.S. manufacturing industries: Evidence from the annual survey of manufactures. Quart. J. Econom. 109(2) 367-397.

Berman, E., J. Bound, S. Machin. 1998. Implications of skill-biased technological change: International evidence. Quart. J. Econom. 113(4) 1245-1279.

Bhagwati, J., A. Panagariya, T. N. Srinivasan. 2004. The muddles over outsourcing. J. Econom. Perspectives 18(4) 93-114.

Blinder, A. S. 2006. Offshoring: The next industrial revolution? Foreign Affairs 85(2) 113-128.

BLS. 2004. Worker displacement survey 2001-2003. http://www.bls. gov/cps.

Brennan, R. L., D. J. Prediger. 1981. Coefficient lambda: Some uses, misuses, and alternatives. Educational Psych. Measurement 41(3) 687-699.

Bresnahan, T. F., E. Brynjolfsson, L. Hitt. 2002. Information technology, workplace organization, and the demand for skilled labor: Firm-level evidence. Quart. J. Econom. 117(1) 339-376.

Brynjolfsson, E., L. Hitt. 1996. Paradox lost? Firm-level evidence on the returns to information systems spending. Management Sci. 42(4) 541-558.
Bryson, J. R. 2001. Services and internationalisation: Annual report on the progress of research into service activities in Europe in 1998. Service Indust. J. 21(1) 227-240.

Carmel, E., R. Agarwal. 2002. The maturation of offshore sourcing of information technology work. MIS Quart. Executive 1(2) 65-77.

Carmel, E., P. Tjia. 2001. Offshoring Information Technology: Sourcing and Outsourcing to a Global Workforce. Cambridge University Press, Cambridge, UK.

Chase, R. B. 1981. The customer contact approach to services: Theoretical bases and practical extensions. Oper. Res. 29(4) 698-706.

Choudhury, V., R. Sabherwal. 2003. Portfolios of control in outsourced software development projects. Inform. Systems Res. 14(3) 291-314.

Cohen, J. 1968. Weighted kappa: Nominal scale agreement with provision for scaled disagreement or partial credit. Psych. Bull. 70(4) 213-220.

Cohendet, P., W. E. Steinmueller. 2000. The codification of knowledge: A conceptual and empirical examination. Indust. Corporate Change 9(2) 195-209.

Daft, R. L., R. H. Lengel. 1984. Information richness: A new approach to managerial behavior and organizational design. L. L. Cummings, B. M. Staw, eds. Research in Organizational Behavior, Vol. 6. JAI Press, Greenwich, CT, 191-225.

Davenport, T. H. 2005. The coming commoditization of processes. Harvard Bus. Rev. 83(6) 1-8.

Davis, J. B. 1999. Is trade liberalization an important cause of increasing U.S. wage inequality? The interaction of theory and policy. Rev. Soc. Econom. 57(4) 488-506.

Deardorff, A. V. 2000. Policy implications of the trade and wages debate. Rev. Internat. Econom. 8(3) 478-496.

Deardorff, A. V., D. S. Hakura. 1994. Trade and wages-What are the questions? J. Bhagwati, M. H. Kosters, eds. Trade and Wages: Leveling Wages Down? AEI Press, Washington, D.C., 76-107.

Dedrick, J., V. Gurbaxani, K. L. Kraemer. 2003. Information technology and economic performance: A critical review of empirical evidence. ACM Comput. Surveys 35(1) 1-28.

Dehejia, R. H., S. Wahba. 2002. Propensity score-matching methods for nonexperimental causal studies. Rev. Econom. Statist. 84(1) 151-161.

Dehning, B., V. J. Richardson, R. W. Zmud. 2003. The value relevance of announcements of transformational information technology investments. MIS Quart. 27(4) 637-656.

Demarie, S. M., M. A. Hitt. 2000. Strategic implications of the information age. J. Labor Res. 21(3) 419-429.

Drezner, D. W. 2004. The outsourcing bogeyman. Foreign Affairs 83(3) 22-35.

Engardio, P. 2006. The future of outsourcing: How IT is transforming industries and changing the way we work. Bus. Week (3969) 50-64.

Engardio, P., B. Einhorn, M. Kripalani, A. Reinhardt, B. Nussbaum, P. Burrows. 2005. Outsourcing innovation. Bus. Week (3925) 84-91.

Evans, P. B., T. S. Wurster. 1997. Strategy and the new economics of information. Harvard Bus. Rev. 75(5) 71-82.

Feenstra, R. C. 1998. Integration of trade and disintegration of production in the global economy. J. Econom. Perspectives 12(4) 31-50.

Feenstra, R. C., G. H. Hanson. 1996. Globalization, outsourcing, and wage inequality. Amer. Econom. Rev. Papers Proc. 86(2) 240-245. 
Florida, R. 2005. The world is spiky. Atlantic Monthly 296(3) 48-51.

Fornell, C., S. Mithas, F. Morgeson, M. S. Krishnan. 2006. Customer satisfaction and stock prices: High returns, low risk. J. Marketing 70(1) 3-14.

Friedberg, R. M., J. Hunt. 1995. The impact of immigrants on host country wages, employment and growth. J. Econom. Perspectives 9(2) 23-44.

Friedman, T. L. 2005. The World Is Flat: A Brief History of the TwentyFirst Century. Farrar, Straus and Giroux, New York.

Gershenson, J. K., G. J. Prasad, Y. Zhang. 2003. Product modularity: Definitions and benefits. J. Engrg. Design 14(3) 295-313.

Gordon, R. J. 2000. Does the "new economy" measure up to the great inventions of the past? J. Econom. Perspectives 14(4) 49-74.

Gosain, S., A. Malhotra, O. A. El Sawy. 2005. Coordination for flexibility in e-business supply chains. J. Management Inform. Systems 21(3) 7-45.

Hagel, III, J., M. Singer. 1999. Unbundling the corporation. Harvard Bus. Rev. 77(2) 133-141.

Hamm, S. 2006. Big blue shift. Bus. Week (3987) 108-110.

Han, K., R. J. Kauffman, B. R. Nault. 2005. Does IT outsourcing pay off? Evidence from industry-level data. Proc. 10th Annual INFORMS Conf. Inform. Systems Tech., CIST, San Francisco, CA.

Hayward, B. M. 2004. Management update: Offshore outsourcing has not caused millions of jobs to disappear. Gartner, ID G00122401 (August 18).

Hirschheim, R., C. Loebbecke, M. Newman, J. Valor. 2005. Offshoring and its implications for the information systems discipline. D. Avison, D. Galletta, eds. Proc. 26th Internat. Conf. Inform. Systems. Association for Information Systems, 1003-1018.

Holland, P., D. B. Rubin. 1983. On lord paradox. H. Wainer, S. Messick, eds. Principles of Psychological Measurement: A Festschrift for Frederic Lord. Erlbaum, Hillsdale, NJ, 3-25.

Huber, G. P. 1990. A theory of the effects of advanced information technologies on organizational design, intelligence, and decision making. Acad. Management Rev. 15(1) 47-71.

Jarvenpaa, S. L., B. Ives. 1990. Information technology and corporate strategy: A view from the top. Inform. Systems Res. 1(4) 351-376.

Jensen, P. D. O., J. F. Kirkegaard, N. S. Laugesen. 2006. Offshoring in Europe-Evidence of a two-way street from Denmark. Working paper, Institute for International Economics, Washington, D.C.

Karmarkar, U. 2004. Will you survive the service revolution? Harvard Bus. Rev. 82(6) 101-107.

Kauffman, R. J., P. Weill. 1989. An evaluative framework for research on the performance effects of information technology investments. J. I. DeGross, J. C. Henderson, B. R. Konsynski, eds. Proc. 10th Internat. Conf. Inform. Systems, Association for Information Systems, Boston, MA, 377-388.

Kellogg, D. L., R. B. Chase. 1995. Constructing an empirically derived measure for customer contact. Management Sci. 41(11) 1734-1749.

Kishore, R., S. Pant. 2005. Enhancing innovation through social capital in offshore business process outsourcing. First Internat. Conf. Management of Globally Distributed Work, IIM Bangalore, Bangalore, India, 129-139.

Krugman, P. 2000. Technology, trade and factor prices. J. Internat. Econom. 50(1) 51-71.
Lacity, M. C., D. F. Feeny, L. P. Willcocks. 2003. Transforming a backoffice function: Lessons from BAE systems' experience with an enterprise partnership. MIS Quart. Executive 2(2) 86-103.

Lawrence, R. Z., M. J. Slaughter. 1993. International trade and American wages in the 1980s: Giant sucking sound or small hiccup? Brookings Papers Econom. Activity (2) 161-226.

Levy, F., A. Goelman. 2005. Offshoring and radiology. L. Brainard, S. Collins, eds. The Offshoring of White Collar Occupations. Brookings Institution, Washington, D.C.

Levy, F., R. J. Murnane. 1992. U.S. earnings levels and earnings inequality: A review of recent trends and proposed explanations. J. Econom. Literature 30(3) 1333-1381.

Levy, F., R. J. Murnane. 2004. The New Division of Labor: How Computers Are Creating The Next Job Market. Russell Sage Foundation, New York.

Lewin, A. Y., V. Couto. 2006. Next generation offshoring: The globalization of innovation. Survey report, ISBN 978-0-97951400-5, Duke Center for International Business Education and Research (CIBER), and Booz, Allen and Hamilton, Durham, NC.

Lucas, H. C. 1993. The business value of information technology: A historical perspective and thoughts for future research. R. D. Banker, R. J. Kauffman, M. A. Mahmood, eds. Strategic Information Technology Management: Perspectives on Organizational Growth and Competitive Advantage. Idea Group Publishing, Harrisburg, PA, 359-374.

Machin, S., J. Van Reenen. 1998. Technology and changes in skill structure: Evidence from seven OECD countries. Quart. J. Econom. 113(4) 1215-1244.

Malone, T. W., K. Crowston, J. Lee, B. Pentland, C. Dellarocas, G. Wyner, J. Quimby, C. S. Osborn, A. Bernstein, G. Herman, M. Klein, E. O'Donnell. 1999. Tools for inventing organizations: Toward a handbook of organizational processes. Management Sci. 45(3) 425-443.

Mann, C. L. 2003. Globalization of IT services and white collar jobs: The next wave of productivity growth. Report PB03-11, Institute for International Economics, Washington, D.C., December 2003.

Martin, R. 2006. What innovation advantage? Bus. Week (3967) 102.

May, C. 2002. The political economy of proximity: Intellectual property and the global division of information labour. New Political Econom. 7(3) 317-342.

McDougall, P. 2006. IBM's India ambition. Inform. Week (March 13) 22-24.

McKinsey Global Institute. 2003. Offshoring: Is It a Win-Win Game? McKinsey Global Institute, San Francisco, CA.

Mithas, S., J. L. Jones. 2007. Do auction parameters affect buyer surplus in e-auctions for procurement? Production Oper. Management 16(4) 455-470.

Mithas, S., M. S. Krishnan. 2007. Human capital and institutional effects in the compensation of information technology professionals in the United States. Management Sci. Forthcoming.

Mithas, S., D. Almirall, M. S. Krishnan. 2006. Do CRM systems cause one-to-one marketing effectiveness? Statist. Sci. 21(2) 223-233.

Mithas, S., M. S. Krishnan, C. Fornell. 2005a. Why do customer relationship management applications affect customer satisfaction? J. Marketing 69(4) 201-209. 
Mithas, S., N. Ramasubbu, M. S. Krishnan, V. Sambamurthy. 2005b. Information technology infrastructure capability and firm performance: An empirical analysis. Working paper, Ross School of Business, University of Michigan, Ann Arbor.

Mithas, S., A. R. Tafti, I. R. Bardhan, J.M. Goh. 2007. Resolving the profitability paradox of information technology: Mechanisms and empirical evidence. Working paper, Robert H. Smith School of Business, University of Maryland, College Park, MD.

Olson, G. M., J. S. Olson. 2000. Distance matters. Human-Comput. Interaction 15(2) 139-178.

Parasuraman, A., V. A. Zeithaml, L. L. Berry. 1988. SERVQUAL: A multiple-item scale for measuring consumer perceptions of service quality. J. Retailing 64(1) 12-40.

Paulk, M. C. 1995. How ISO 9001 compares with the CMM. IEEE Software 12(1) 74-83.

Perreault, W. D., L. E. Leigh. 1989. Reliability of nominal data based on qualitative judgments. J. Marketing Res. 26(May) 135-148.

Porter, M. E., V. E. Millar. 1985. How information gives you competitive advantage. Harvard Bus. Rev. 63(4) 149-160.

Prahalad, C. K., M. S. Krishnan. 2004. The building blocks of global competitiveness. Optimize 3(9) 30-40.

Purvis, R. L., V. Sambamurthy, R. W. Zmud. 2000. The development of knowledge embeddedness in CASE technologies within organizations. IEEE Trans. Engrg. Management 47(2) 245-257.

Rai, A., R. Patnayakuni, N. Patnayakuni. 1997. Technology investment and business performance. Comm. ACM 40(7) 89-97.

Rai, A., R. Patnayakuni, N. Seth. 2006. Firm performance impacts of digitally-enabled supply chain integration capabilities. MIS Quart. 30(2) 225-246.

Ramasubbu, N., S. Mithas, M. S. Krishnan. 2007. High tech, high touch: The effect of employee skills and customer heterogeneity on customer satisfaction with enterprise system support services. Decision Support Systems. Forthcoming.

Ramasubbu, N., S. Mithas, M. S. Krishnan, C. F. Kemerer. 2007. Work dispersion, process-based learning and offshore software development performance. Working paper, Singapore Management University, Singapore.

Rezaee, Z., A. Sharbatoghlie, R. Elam, P. L. McMickle. 2002. Continuous auditing: Building automated auditing capability. Auditing 21(1) 147-163.

Ricadela, A. 2006. Invented in India. InformationWeek (1076) 47-52.

Richardson, J. D. 1995. Income inequality and trade: How to think, what to conclude. J. Econom. Perspectives 9(3) 33-55.

Rodrik, D. 1997. Has Globalization Gone Too Far? Institute for International Economics, Washington, D.C.

Rosenbaum, P. R., D. B. Rubin. 1983. The central role of the propensity score in observational studies for causal effects. Biometrika 70(1) 41-55.

Rottman, J. W., M. C. Lacity. 2004. Twenty practices for offshore sourcing. MIS Quart. Executive 3(3) 117-130.

Russ-Eft, D. 2004. Customer service competencies: A global look. Human Resource Development Internat. 7(2) 211-231.

Rust, R. T., B. Cooil. 1994. Reliability measures for qualitative data: Theory and implications. J. Marketing Res. 31(1) 1-14.
Sachs, J. D., H. J. Shatz. 1996. U.S trade with developing countries and wage inequality. Amer. Econom. Rev. (Papers and Proceedings) 86(2) 234-239.

Sambamurthy, V., A. Bharadwaj, V. Grover. 2003. Shaping agility through digital options: Reconceptualizing the role of information technology in contemporary firms. MIS Quart. 27(2) 237-263.

Samuelson, P. A. 2004. Where Ricardo and Mill rebut and confirm arguments of mainstream economists supporting globalization. J. Econom. Perspectives 18(3) 135-146.

Slaughter, M. J. 1998. International trade and labour-market outcomes: Results, questions, and policy options. Econom. J. 108(450) 1452-1462.

Sobel, M. E. 1982. Asymptotic confidence intervals for indirect effects in structural equations models. S. Leinhart, ed. Sociological Methodology. Jossey-Bass, San Francisco, CA, 290-312.

Sobol, M. G., U. M. Apte. 1995. Domestic and global outsourcing practices of America's most effective IS users. J. Inform. Tech. 10(4) 269-280.

Solovy, A. 2002. Forward progress. Hospitals Health Networks 76(7) $38-48$.

Stolper, W. F., P. A. Samuelson. 1941. Protection and real wages. Rev. Econom. Stud. 9(1) 58-73.

Tafti, A., S. Mithas, M. S. Krishnan. 2007. Information technology and the autonomy-control duality: Toward a theory. Inform. Tech. Management 8(2) 147-166.

Tam, P.-W. 2006. Market is hot for high-skilled in Silicon Valley. Wall Street Journal (February 28) B1, B5.

Thomas, K. W., W. G. Tymon. 1982. Necessary properties of relevant research: Lessons from recent criticisms of the organizational sciences. Acad. Management Rev. 7(3) 345-352.

Thurm, S. 2007. Behind outsourcing: Promise and pitfalls. Wall Street Journal (February 26) B3.

Venkatraman, N. 2004. Offshoring without guilt. Sloan Management Rev. 45(3) 14-15.

Victor, B. 1990. Coordinating work in complex organizations. J. Organ. Behav. 11(3) 187-199.

Ward, W. A. 2006. Manufacturing jobs 2005-2010: Medium-term strategies for long-term realities. Econom. Development J. 5(1) $7-15$.

Whitaker, J., S. Mithas, M. S. Krishnan. 2005. Antecedents of onshore and offshore business process outsourcing. D. Avison, D. Galletta, eds. Proc. 26th Internat. Conf. Inform. Systems, Association for Information Systems, 85-96.

Whitaker, J., S. Mithas, M. S. Krishnan. 2007. A field study of RFID deployment and return expectations. Production Oper. Management 16(5).

Zenger, T. R., W. S. Hesterly. 1997. The disaggregation of corporations: Selective intervention, high-powered incentives, and molecular units. Organ. Sci. 8(3) 209-222.

Zhao, N., D. C. Yen, I. Chang. 2004. Auditing in the e-commerce era. Inform. Management Comput. Security 12(5) 389-400. 